\title{
Human health risk due to consumption of vegetables contaminated with carcinogenic polycyclic aromatic hydrocarbons
}

\author{
Sardar Khan • Qing Cao
}

Received: 22 July 2011 / Accepted: 2 September 2011 / Published online: 14 September 2011

(C) Springer-Verlag 2011

\begin{abstract}
Purpose Polycyclic aromatic hydrocarbons (PAH) are persistent, toxic, and carcinogenic contaminants present in soil ecosystem globally. These pollutants are gradually accumulating in wastewater-irrigated soils and lead to the contamination of vegetables. Food chain contamination with PAH is considered as one of the major pathways for human exposure. This study was aimed to investigate the concentrations of PAH in soils and vegetables collected from wastewater-irrigated fields from metropolitan areas of Beijing, China. Origin of PAH, daily intake, and health risks of PAH through consumption of contaminated vegetables were studied.

Materials and methods Soil samples were collected from the upper horizon $(0-20 \mathrm{~cm})$ of both wastewater-irrigated and reference sites and sieved $(<2 \mathrm{~mm}$ mesh) and then followed by freeze-drying at $-50{ }^{\circ} \mathrm{C}$ and $123 \pm 2 \mathrm{~Pa}$. Standing vegetables were also collected from the same sites used for soil sampling and divided into roots and shoots, thoroughly washed with deionized water, and freeze-dried. PAH were extracted using the Soxhlet method with $200 \mathrm{~mL}$ DCM for $24 \mathrm{~h}$, and the extracts were cleaned
\end{abstract}

Responsible editor: Willie Peijnenburg

S. Khan

Institute of Urban Environment, Chinese Academy of Sciences,

Xiamen, China

Q. Cao

Research Center for Eco-Environmental Sciences,

Chinese Academy of Sciences,

Beijing 100085, People's Republic of China

S. Khan $(\square)$

Department of Environmental Science, University of Peshawar,

Peshawar 25120, Pakistan

e-mail: sardar.khan2008@yahoo.com with silica adsorption chromatography prepared with silica gel, alumina, and capped with anhydrous sodium. The final concentrated extracts (soil and vegetable) were analyzed using gas chromatography-mass spectrometry (Agilent 6890). Bioaccumulation factors, daily intake of PAH, and carcinogenicity of PAH were calculated by different statistical equations.

Results and discussion Results indicate that the soils and grown vegetables were contaminated with all possible carcinogenic PAH (declared by USEPA 2002) except indeno[1,2,3-c,d]pyrene. The highest concentration (242.9 $\mu \mathrm{g} \mathrm{kg}^{-1}$ ) was found for benzo(k)fluoranthene (BkF), while lowest $\left(79.12 \mu \mathrm{g} \mathrm{kg}^{-1}\right)$ for benzo[a]pyrene (BaP). The emission sources of PAH were both pyrogenic and petrogenic in nature. However, the total concentrations of PAH were lower than the permissible limits set by different countries like Canada, Denmark and Germany. Highest total PAH concentration was found in the shoots of Spinacia oleracea L., while lowest in the roots of Raphanus sativus. In this study, the values of total toxic $\mathrm{BaP}$ equivalent (TEQ) through consumption of vegetables were found in order of S. oleracea L.> Lactuca sativa L.> Brassica oleracea L. $>$ Brassica napus $>$ Brassica juncea L. $>R$. sativus $\mathrm{L}$. The data indicate that the daily intake of $\mathrm{BaP}$ through consumption of vegetables for adults were lower than virtually safe dose set by the Dutch National Institute for Public Health and the Environment.

Conclusions Our findings indicate that PAH concentrations in soil and vegetables were lower than their respective permissible limits set by different organizations. However, the highest intake of total PAH was estimated through consumption of $S$. oleracea L. for both adults and children.

Keywords Daily intake $\cdot$ Health risk $\cdot \mathrm{PAH} \cdot$ Vegetables . Wastewater 


\section{Introduction}

Polycyclic aromatic hydrocarbons (PAH) are recalcitrant, mutagenic, and carcinogenic pollutants, prevalent in the environment (air, water, and soil ecosystem) as a result of different anthropogenic activities (Meng et al. 2011; Khan et al. 2008a). This group consists of more than 100 compounds having aromatic rings ranging from two to six with high lipophilicy and low water solubility (Danyi et al. 2009; Zhang et al. 2011). PAH (with three or more aromatic rings) are carcinogenic in nature (Kalf et al. 1995) as shown by experiments on animals in laboratories and implicated different types of cancers (breast, lung, and colon) in human. The International Agency for Research on Cancer (IARC 2004), United States Environmental Protection Agency (USEPA 2002), and European Commission Regulation (ECR 2006) have classified and listed PAH according to their carcinogenicity. The USEPA (2002) grouped benzo[ $a]$ anthracene $(\mathrm{BaA})$, benzo $[a]$ pyrene $(\mathrm{BaP})$, benzo[b]fluoranthene $(\mathrm{BbF})$, chrysene $(\mathrm{Chr})$, benzo[ $k]$ fluoranthene, dibenzo $[a, h]$ anthracene (DBA), and indeno[1,2,3-c,d]pyrene as probable human carcinogens. In metropolitan regions of Tianjin, China, wastewater is used for irrigation. Characteristically, this wastewater contains high concentrations of nutrients and $\mathrm{PAH}$, which are accountable for both benefits and harms in the agriculture sector (Chen et al. 2005; Singh et al. 2004).

Generally, a serious concern exists about the presence of PAH in the environment and their bioaccumulation in food stuffs (Martorell et al. 2010). There are various possible exposure pathways of PAH to humans, but the food chain is one of the most important pathways for the entry of these toxic pollutants into the human body. Food chain contamination with PAH is of increasing concern because of their adverse impacts on the quality of food and health. Bioaccumulation of PAH in vegetables depends on numerous factors including soil characteristics, PAH concentrations, and physiological characteristics of vegetables (Tao et al. 2004). Several PAH exposure pathways exist, but food is considered as the major source ( $70 \%$ of the total exposure) of human to PAH (Falcó et al. 2003; McGrath et al. 2007).

Vegetables grown on wastewater-contaminated soils accumulate $\mathrm{PAH}$ at a concentration enough to cause human health risk. In the past, numerous research studies have demonstrated that vegetables grown on PAH-contaminated soils may take up PAHs (Wennrich et al. 2002). Several mechanisms including sorption (from soil particles), uptake rate through transpiration, volatilization, and redeposition on plant surfaces are responsible for the PAH transfer from soil ecosystem to plant tissues (Fryer and Collins 2003; Wild et al. 2004).

It is necessary to investigate the sources of PAH, origins, pathways, distribution in agricultural soils, and bioaccumu- lation to assess the possible human health risk caused by consumption of PAH-contaminated vegetables. Recently, a number of articles have highlighted the sources, bioaccumulation, and transfer of PAH from contaminated soils (Khan et al. 2008a, b; Zhang et al. 2011). The farming soils contaminated with PAH due to long-term wastewater irrigation result in elevated uptake of PAH into vegetables. Consequently, severe human health risks can be caused by the consumption of PAH-contaminated vegetables. The main objective of this study was to investigate the vegetable uptake of possible carcinogenic PAH from long-term wastewater-irrigated soils and to assess the potential harm to public health.

\section{Materials and methods}

\subsection{Chemical reagents}

All solvents including dichloromethane (DCM) and $n$ hexane purchased from Beijing Chemical Factory were of analytical grade and redistilled in an all-glass system before use. Silica gel, alumina, and sodium sulfate were purchased from Qingdao Haiyang Chemical Co. (Shangdong, China) and were activated at $180^{\circ} \mathrm{C}, 250^{\circ} \mathrm{C}$, and $450^{\circ} \mathrm{C}$, respectively, for at least $12 \mathrm{~h}$ and then kept in desiccators for further uses.

\subsection{Description of study area}

The study area is Beijing, located in northern China with dense population, and generates a large volume of wastewater from industrial, commercial, and domestic sectors. Agricultural soils are usually irrigated with this wastewater to minimize the existing dependency on groundwater resources for irrigation purposes. Furthermore, rapid economic development in China during the last two decades has put a great burden on agricultural lands, and fast urbanization in the study area has also resulted in more wastewater generation and PAH contamination (Khan et al. 2008b).

\subsection{Soil sampling and characterization}

Soil samples were collected from the upper horizon $(0$ $20 \mathrm{~cm}$ ) of both wastewater-irrigated and reference sites according to standard procedures. Four soil samples were collected at each site randomly and then bulked together to form a composite sample. In the laboratory, the fresh soil samples were sieved ( $<2 \mathrm{~mm}$ mesh) and then followed by freeze-drying at $-50^{\circ} \mathrm{C}$ and $123 \pm 2 \mathrm{~Pa}$. Dried samples were sealed in paper sacks and stored at $-20^{\circ} \mathrm{C}$ for further analyses. For initial physicochemical characteristics of the 
soils, subsamples were used according to standard procedures. Soil $\mathrm{pH}$ was (7.9-8.3) measured with $\mathrm{H}_{2} \mathrm{O}(1: 2.5$ ratio), while soil organic content (SOC) was (2.7-6.2\%) measured according to procedure given by Storer (1984).

\subsection{Plant sampling and preparation}

Standing vegetables (grown in the fields, Table 1) were collected from the sites used for soil sampling and divided into roots and shoots, thoroughly washed with deionized water, and dried in freeze-drier (at $-50^{\circ} \mathrm{C}$ and $123 \pm 2 \mathrm{~Pa}$ ). Samples were powdered and stored at $-20^{\circ} \mathrm{C}$ for further analysis.

\subsection{PAH extraction and analysis}

Soxhlet method was used for extraction of possible human carcinogenic PAH from both soil and vegetables. Freezedried samples $(10 \mathrm{~g})$ were taken and mixed with anhydrous sodium sulfate $(2 \mathrm{~g})$ and extracted with $200 \mathrm{~mL}$ DCM for $24 \mathrm{~h}$. The rotary evaporator was used to remove the DCM and reduced the volume to $1 \mathrm{~mL}$ under gentle flow of nitrogen, then followed by cleaning the extract with silica adsorption chromatography prepared with silica gel, alumina, and capped with anhydrous sodium sulfate and eluted with $60 \mathrm{~mL}$ mixture of hexane and DCM $(7: 3, v / v)$. At last, the eluted fraction was again reduced to $1 \mathrm{~mL}$ under gentle flow of nitrogen for PAH determination. The final concentrated extracts (soil and vegetable) were analyzed using gas chromatography-mass spectrometry (GC-MS, Agilent 6890), equipped with a 5973 mass selective detector under the selected ion monitoring (SIM) mode. A silica fused capillary column (HP-5) with $60 \mathrm{~m} \times 0.25 \mathrm{~mm}$ inner diameter $\times 0.25 \mu \mathrm{m}$ film thickness was used, while helium was selected as the carrier gas at a constant flow rate of $1 \mathrm{~mL} \min ^{-1}$. The GC oven temperature was programmed from $50^{\circ} \mathrm{C}(2 \mathrm{~min})$ to $200^{\circ} \mathrm{C}(2 \mathrm{~min})$ at $10^{\circ} \mathrm{C} \mathrm{min}^{-1}$, then to $290^{\circ} \mathrm{C}$ at $20^{\circ} \mathrm{C} \mathrm{min}^{-1}$ and held for $8 \mathrm{~min}$. The injector and detector temperatures were $280^{\circ} \mathrm{C}$ and $290^{\circ} \mathrm{C}$, respectively. Mass spectra were acquired at the electron ionization mode with an electron multiplier voltage of $1,906 \mathrm{eV}$. For identification, the SIM mode was carried out using the

Table 1 English, local, and botanical names of the studied vegetables

\begin{tabular}{lll}
\hline English name & Local name & Botanical name \\
\hline Radish & Luobo & R. sativus L. \\
Green cabbage & Gaicai & B. juncea L. \\
Spinach & Bocai & S. oleracea L. \\
Cauliflower & Huacai & B. oleracea L. \\
Turnip & Youcai & B. napus \\
Lettuce & Wosun & L. sativa L. \\
\hline
\end{tabular}

molecular ions selective for individual PAH. Chromatographic data were collected and processed using GC-MS Chemstation software.

\subsection{Quality control}

For accuracy and precision of the extraction procedure, experiments on PAH recovery were carried out by spiking a known concentration of PAH standards $\left(2 \mu \mathrm{g} \mathrm{g}^{-1}\right)$ in uncontaminated soil and plant materials. The results showed satisfactory recovery, with the average value ranging from $89.5 \pm 6.7 \%$ to $104.9 \pm 5.1 \%$ for soil and plant materials, respectively.

\subsection{Data analysis}

\subsubsection{Bioaccumulation factors}

PAH concentrations in the extracts of soils, roots, and shoots were calculated on the basis of dry weight. Root concentration factors (RCFs), shoot concentration factors (SCFs), and fruit concentration factors (FCFs) are often used for contaminant concentrations in plants because soilto-plant transfer is one of the major pathways for pollutants to enter the food chain. RCFs and SCFs were calculated as follows:

1. $\mathrm{RCF}=C_{\text {root }} / C_{\text {soil }}$

2. $\mathrm{SCF}=C_{\text {shoot }} / C_{\text {soil }}$

3. $\mathrm{FCF}=C_{\text {fruit }} / C_{\text {soil }}$

where $C_{\text {root }}, C_{\text {shoot }}, C_{\text {fruit }}$, and $C_{\text {soil }}$ represent the contaminant concentration in root, shoot, fruit, and soil on dry weight basis, respectively.

\subsubsection{Daily intake of PAH}

The daily intake of PAH (DI-PAH) through consumption of PAH-contaminated vegetable was determined by the following equation.

$\mathrm{DI}-\mathrm{PAH}=\frac{C_{\mathrm{PAH}} \times C_{\text {factor }} \times V_{\text {intake }}}{B_{\text {weight }}}$

where $C_{\mathrm{PAH}}, C_{\text {factor }}, V_{\text {intake }}$, and $B_{\text {weight }}$ represent the $\mathrm{PAH}$ concentrations in vegetables (in micrograms per kilogram), conversion factor, daily intake of vegetables, and average body weight, respectively. To convert fresh weight of vegetable into dry weight, a conversion factor $(0.085)$ was used (Rattan et al. 2005). Average daily vegetable intake for adults and children were considered of 0.345 and $0.232 \mathrm{~kg}$ person ${ }^{-1} \mathrm{day}^{-1}$, respectively, while the average adult and children body weights were considered of 63.9 and $32.7 \mathrm{~kg}$, respectively, as used in the previous studies (Ge 1992). 


\subsubsection{Risk assessment of PAH in vegetables}

The total toxic BaP equivalent (TEQ) for selected PAH was calculated using the equation as mentioned by Wang et al. (2011).

$\mathrm{TEQ}=\sum C_{\mathrm{PAH}} \times \mathrm{TEF}$

where $C_{\mathrm{PAH}}$ is the individual $\mathrm{PAH}$ concentrations in vegetables (in micrograms per kilogram) and TEF represent corresponding toxic equivalency factor set for PAH by USEPA (2002). All the data were statistically analyzed for mean of triplicates using Microsoft excel software (Microsoft 2007), while bioaccumulation factor, DI-PAH, and TEQ were calculated using different statistical equations.

\section{Results}

\subsection{PAH concentrations and sources in soil}

Table 2 summarizes the concentrations of PAH in soil samples collected from the study area. A wide range of PAH distribution was observed in the soils and ranged from 56.4 to $432 \mu \mathrm{g} \mathrm{kg}^{-1}$, with mean concentrations of 79.1$243 \mu \mathrm{g} \mathrm{kg}^{-1}$. However, total PAH concentrations in the soils ranged from 378 to $1,626 \mu \mathrm{g} \mathrm{kg}^{-1}$ and found lower than the Netherlands' permissible limit $\left(1 \mathrm{mg} \mathrm{kg}^{-1}\right.$ for 10 $\mathrm{PAH})$ set for soil. All the selected PAH are declared as possible carcinogenic as enlisted by the US Environmental Protection Agency (USEPA 2002). In order to indentify the emission sources of PAH, ratios of different PAH were used indicating both pyrogenic and petrogenic origins (Khan et al. 2008a). A regression analysis was also performed to observe the relationship between SOC and total PAH in soil. A weak linear relationship $\left(R^{2}\right.$ ranged from 0.512 to 0.624) was found between SOC and total PAH.

\subsection{PAH concentrations in vegetables}

The selected PAH were detected in the edible parts (roots, shoots, and fruits) of the vegetables as given in Table 3.

Table 2 PAH concentrations (in micrograms per kilogram, dry weight) in soil samples

\begin{tabular}{lccc}
\hline PAH & Min & Max & Mean \\
\hline Benzo $[a]$ anthracene & 123 & 295 & 185 \\
Chrysene & 56.4 & 184 & 108 \\
Benzo $[b]$ fluoranthene & 95.8 & 260 & 163 \\
Benzo $k]$ fluoranthene & 100 & 432 & 243 \\
Benzo $[a]$ pyrene & 189 & 207 & 79.1 \\
Dibenzo $[a, h]$ anthracene & 249 & 251 & 100 \\
\hline
\end{tabular}

Mean concentrations of PAH in the roots of Raphanus sativus L. and Brassica napus ranged from 1.16 to $46.4 \mu \mathrm{g} \mathrm{kg}^{-1}$ and 5.79 to $51.94 \mu \mathrm{g} \mathrm{kg}^{-1}$, respectively, while in the shoots of Brassica juncea L., Spinacia oleracea L., and Lactuca sativa L. ranged from 10 to 55.6, 17.2 to 175 , and 11.6 to $148 \mu \mathrm{g} \mathrm{kg}^{-1}$, respectively. Furthermore, PAH concentrations in the fruits of Brassica oleracea $\mathrm{L}$. ranged from 6.94 to $77.7 \mu \mathrm{g} \mathrm{kg}^{-1}$. Highest total PAH concentration $\left(542 \mu \mathrm{g} \mathrm{kg}^{-1}\right)$ was detected in the shoots of $S$. oleracea L., while the lowest total PAH concentration $\left(125 \mu \mathrm{g} \mathrm{kg}^{-1}\right)$ was observed in the roots of R. sativus L.

\subsection{Bioaccumulation factors in vegetables}

The bioaccumulation factors calculated for roots, shoots, and fruits are given in Table 4. RCFs for R. sativus L. and $B$. napus ranged from 0.01 to 0.25 and 0.05 to 0.41 , respectively, while SCFs for B. juncea L., S. oleracea L., and $L$. sativa $L$. ranged from 0.1 to $0.5,0.1$ to 1.0 , and 0.1 to 0.8 , respectively. The values of FCFs for $B$. oleracea $\mathrm{L}$. ranged from 0.06 to 0.6 . Generally, the bioaccumulation factors decreased with the increase of ring numbers in $\mathrm{PAH}$ compounds.

\subsection{Risk assessment of PAH}

The estimated DI-PAH values were not constant for all selected PAH and also highly varied along with the types of vegetables. In order to estimate the DI-PAH, the average PAH concentrations in vegetables and consumption were used. The calculated DI-PAH values for both adults and children through consumption of vegetables are given in Table 5. Daily intake of individual PAH by adults through consumption of vegetables ranged from 0.0005 to $0.0805 \mu \mathrm{g} \mathrm{kg}^{-1}$ body weight day ${ }^{-1}$, while from 0.0007 to $0.1058 \mu \mathrm{g} \mathrm{kg}^{-1}$ body weight day ${ }^{-1}$ for children. In order to quantify the carcinogenicity of the selected PAH, TEF were used. In this study, TEF values suggested for PAH by USEPA (2002) and BaP toxicological value are used to estimate the carcinogenic potency for other PAH. The mean TEQ values for individual $\mathrm{PAH}$ such as $\mathrm{BaA}, \mathrm{Chr}, \mathrm{BbF}$, benzo $[k]$ fluoranthene $(\mathrm{BkF}), \mathrm{BaP}$, and DBA were 9.20, 0.07, 5.0, 0.54, 9.66, and 15.33, respectively, while it ranged from 23.93 to 70.39 for the mean total PAH in each vegetable. The highest value (70.39) was found for $S$. oleracea L., while the lowest (23.93) for $R$. sativus L.

\section{Discussion}

Wastewater irrigation is usually considered as one of the main anthropogenic sources of contamination of soils with 
Table 3 Mean PAH concentrations (in micrograms per kilogram, dry weight) in vegetables collected from the study area

\begin{tabular}{|c|c|c|c|c|c|c|}
\hline PAHs & R. sativus L. $(n=8)$ & B. juncea L. $(n=10)$ & S. oleracea L. $(n=5)$ & B. oleracea L. $(n=7)$ & B. napus $(n=8)$ & L. sativa $\mathrm{L} .(n=12)$ \\
\hline $\mathrm{BaA}$ & 46.4 & 55.6 & 175 & 74.2 & 51.9 & 148 \\
\hline $\mathrm{Chr}$ & 16.3 & 54.2 & 134 & 65 & 44.4 & 130 \\
\hline $\mathrm{BbF}$ & 21.2 & 32.6 & 97.9 & 65.2 & 34.2 & 48.9 \\
\hline $\mathrm{BkF}$ & 24.3 & 48.6 & 92.8 & 77.7 & 31.6 & 48.6 \\
\hline $\mathrm{BaP}$ & 7.91 & 7.91 & 12 & 11.1 & 11.1 & 7.91 \\
\hline DBA & 9 & 10 & 29.9 & 11 & 12 & 20 \\
\hline
\end{tabular}

PAHs (Tang et al. 2005; Ye et al. 2006; Khan et al. 2008a, b; Zhang et al. 2011). In this study we focused on those PAH who were declared as possible human carcinogens by USEPA (2002) and only six PAH including $\mathrm{Chr}, \mathrm{BaA}, \mathrm{BbF}$, $\mathrm{BkF}, \mathrm{BaP}$, and DBA were detected in both soils and vegetables, while indeno[1,2,3-c,d]pyrene was not found. Bioaccumulation of these PAH in edible parts of vegetables is responsible for major health concern. The benchmark contamination levels for PAH vary from country to country, but so far many countries including China have not established the tolerable limits for PAH in both soil and vegetables. Furthermore, the results indicated that selected PAH concentrations in the soils were generally lower than those previously reported in the literature (Tang et al. 2005; Dai et al. 2006), while consistent with those reported by Zhang et al. (2011). Except one site, $\mathrm{BaA}$ and $\mathrm{BaP}$ concentrations were found within the maximum permissible limits set for soil in the Netherlands (Kalf et al. 1997). In order to identify the natural and anthropogenic origin of PAH in soil, different PAH ratios were used (Sanders et al. 2002) and were found that selected PAH were of both pyrogenic and petrogenic in origin. These findings also agreed with the data reported previously (Tang et al. 2005; Zhang et al. 2011).

Bioaccumulation of PAH in the edible parts (roots or shoots) of vegetables depends on the type of vegetable, SOC, concentration in soil, and transfer routs. In the past, several research works have demonstrated that SOC acts as a huge sink of PAH and other organic pollutants and reduces the bioavailability of PAH (Hwang and Cutright 2004). Generally, the availability of PAH decreases with increasing SOC, therefore the soil with high values of SOC allows less bioaccumulation of PAH in vegetables. Bioaccumulation factor is one of the key pathways of human exposure to PAH through consumption of vegetable and/or food chain. In order to investigate the health risk associated with $\mathrm{PAH}$, it is essential to assess the bioaccumulation factor. The values of these factors depend on types of PAH, physiology of plant, and contents of PAH in growing media. In this study, the bioaccumulation factor was found $<1$, except for Chr in L. sativa L. and S. oleracea L., therefore most of the studied vegetables were not hyperaccumulators. PAH uptake rate and bioaccumulation are also depending on their solubility, therefore high molecular weight PAH have less solubility, low vapor pressure, and high octanol-water $\left(K_{\mathrm{OW}}\right)$ and octanol-air $\left(K_{\mathrm{OA}}\right)$ partitioning coefficients. In the present study, the selected PAH have high molecular weights for which root uptake is usually considered as the major rout for bioaccumulation in plant roots and shoots (Fismes et al. 2002). However, in the study area, dustfall samples collected in both heating and nonheating seasons were also contaminated with these high molecular weight $\mathrm{PAH}(\mathrm{BaA}, \mathrm{Chr}, \mathrm{BbF}, \mathrm{BkF}, \mathrm{BaP}$, and DBA ranged from 0.02 to $0.65,0.02$ to $0.33,0.03$ to $0.25,0.02$ to $0.29,0.01$ to 0.21 , and $0.01 \mu \mathrm{g} \mathrm{g}^{-1}$, respectively, while $\sum 16$ PAH ranged $0.72-40.45 \mu \mathrm{g} \mathrm{g}^{-1}$ ) as reported by Zhang et al. (2008), which means that dustfall may be contribute to PAH contamination of soil and vegetables. In this study, highest PAH concentration was found in S. oleracea L. followed by L. sativa $\mathrm{L}$. The trends of PAH concentrations in vegetables were found in the order of $S$. oleracea $\mathrm{L} .>L$. sativa $\mathrm{L} .>B$. oleracea $\mathrm{L} .>B$. juncea $\mathrm{L} .>B$. napus $>R$. sativus $\mathrm{L}$. A wide

Table 4 Mean values of bioaccumulation factors of PAH in vegetables collected from study area

\begin{tabular}{|c|c|c|c|c|c|c|}
\hline PAH & R. sativus L. $(n=8)$ & B. juncea L. $(n=10)$ & S. oleracea L. $(n=5)$ & B. oleracea L. $(n=7)$ & B. napus $(n=8)$ & L. sativa $\mathrm{L} .(n=12)$ \\
\hline $\mathrm{BaA}$ & 0.25 & 0.3 & 0.8 & 0.4 & 0.28 & 0.8 \\
\hline $\mathrm{Chr}$ & 0.15 & 0.5 & 1 & 0.6 & 0.41 & 1.2 \\
\hline $\mathrm{BbF}$ & 0.13 & 0.2 & 0.5 & 0.4 & 0.21 & 0.3 \\
\hline $\mathrm{BkF}$ & 0.1 & 0.2 & 0.3 & 0.32 & 0.13 & 0.2 \\
\hline $\mathrm{BaP}$ & 0.1 & 0.1 & 0.1 & 0.14 & 0.14 & 0.1 \\
\hline DBA & 0.09 & 0.1 & 0.2 & 0.11 & 0.12 & 0.2 \\
\hline
\end{tabular}


Table 5 DI-PAH (in micrograms per kilogram body weight per day) by adults and children through consumption of vegetables

\begin{tabular}{llllll}
\hline PAH (adults) & $\begin{array}{l}\text { R. sativus } \\
\text { L. }(n=8)\end{array}$ & $\begin{array}{l}\text { B. juncea } \\
\text { L. }(n=10)\end{array}$ & $\begin{array}{l}\text { S. oleracea } \\
\text { L. }(n=5)\end{array}$ & $\begin{array}{l}\text { B. oleracea } \\
\text { L. }(n=7)\end{array}$ & $\begin{array}{l}\text { B. napus } \\
(n=8)\end{array}$ \\
\hline BaA & 0.0213 & 0.0255 & 0.0805 & 0.0341 & 0.0238 \\
L. sativa $(n=12)$
\end{tabular}

range of variation in RCFs and SCFs could be contributed to their difference in soil concentrations, soil physicochemical properties, and low solubility of PAH.

As mentioned earlier, DI-PAH and TEF were used to assess the human health risk and quantify the carcinogenicity of the selected PAH associated with consumption of PAH-contaminated vegetables. The results indicated that highest total TEQ value was observed in S. oleracea L., while lowest for $R$. sativus L. In this study, the values of total TEQ through consumption of vegetables were found in the order of $S$. oleracea L. $>$ L. sativa L. $>$ B. oleracea L.> $B$. napus $>B$. juncea L. $>R$. sativus $\mathrm{L}$. The data indicate that the daily intake of BaP through consumption of vegetables for adults were lower than $0.0005 \mu \mathrm{g} \mathrm{kg}$ body weight day ${ }^{-1}$ (virtually safe dose) set by the Dutch National Institute for Public Health and the Environment. However, daily intake of $\mathrm{BaP}$ exceeded this safe limit through consumption of $S$. oleracea L., B. oleracea L., and $B$. napus for children. Furthermore, the highest intake of total PAH was estimated through consumption of S. oleracea L. for both adults and children. However, there are also other routes such as dermal contact and inhalation through which PAH exposures of human beings occur (Chen and Liao 2006). To limit human exposure to PAH, it is essential to set the environmental standards for PAH in soils, water, vegetables, and other food stuffs and public health policy should emphasis the concern of these exposures on priority basis.

\section{Conclusions}

On the basis of findings, it is concluded that the PAH concentrations in soil and vegetable did not exceed the permissible limits. Bioaccumulation of PAH was found in the order of $S$. oleracea L. $>$ L. sativa L. $>$ B. oleracea L. $>B$. juncea L. $>$ B. napus $>R$. sativus L. However, the highest intake of total PAH was estimated through consumption of $S$. oleracea L. for both adults and children. DI-BaP through consumption of vegetables for adults were lower than the safe dose but exceeded this safe limit through consumption of S. oleracea L., B. oleracea L., and B. napus for children. It is necessary to have maximum acceptable limits for PAH in different food stuffs and environmental media to protect the public from exposure.

Acknowledgments This research work was financially supported by the Chinese Ministry of Science and Technology (2007CB407304). Sardar Khan would like to thank Higher Education Commission, Islamabad, Pakistan for providing scholarship. We thank the anonymous reviewers for their valuable comments.

\section{References}

Chen SC, Liao CM (2006) Health risk assessment on human exposed to environmental polycyclic aromatic hydrocarbons pollution sources. Sci Total Environ 366:112-123

Chen Y, Wang C, Wang Z (2005) Residues and source identification of persistent organic pollutants in farmland soils irrigated by effluents from biological treatment plants. Environ Int 31:778-783

Dai J, Xu M, Chen J, Yang X, Ke Z (2006) PCDD/F, PAH and heavy metals in the sewage sludge from six wastewater treatment plants in Beijing, China. Chemosphere 66:353-361

Danyi S, Bose F, Brasseur C, Schneider YJ, Larondelle Y, Pussemier L, Robbens J, DeSaeger S, Maghuin-Rogister G, Scippo ML (2009) Analysis of EU priority polycyclic aromatic hydrocarbons in food supplements using high performance liquid chromatography coupled to an ultraviolet, diode array or fluorescence detector. Anal Chim Acta 633:293-299

ECR (2006) European Commission Regulation No 1881/2006 of 19th December, 2006, setting maximum levels for certain contami- 
nants in foodstuffs. http://eurlex.europa.eu/LexUriServ/LexUriServ. do?uri=OJ:L:2006:364:0005:0024:EN:PDF. Accessed 12 June 2011

Falcó G, Domingo JL, Llobet JM, Teixidó A, Casas C, Müller L (2003) Polycyclic aromatic hydrocarbons in foods: human exposure through the diet in Catalonia, Spain. J Food Prot 66:2325-2331

Fismes J, Perrin-Ganier C, Empereur-Biosoonnet P, Morel JL (2002) Soil-to-root transfer and translocation of polycyclic aromatic hydrocarbons by vegetables grown on industrial contaminated soils. J Environ Qual 31:1649-1656

Fryer ME, Collins CD (2003) Model intercomparison for the uptake of organic chemicals by plants. Environ Sci Technol 37:1617-1624

Ge KY (1992) The status of nutrient and meal of Chinese in the 1990s. Beijing People's Hygiene Press, Beijing, pp 415-434

Hwang S, Cutright TJ (2004) Preliminary evaluation of PAH sorptive changes in soil by Soxhlet extraction. Environ Int 30:151-158

IARC (2004) International Agency for Research of Cancer. Overall evaluations of carcinogenicity: an updating of IARC monographs. Int Agency Res Cancer, 7

Kalf DF, Crommentuijn GH, Posthumus R, Van de Plassche EJ (1995) Integrated environmental quality objectives for polycyclic aromatic hydrocarbons (PAHs). National Institute of Public Health and the Environment, Bilthoven, $\mathrm{p} 12$

Kalf DF, Crommentuijn T, Van de Plassche EJ (1997) Environmental quality objectives for 10 polycyclic aromatic hydrocarbons (PAHs). Ecotoxicol Environ Saf 36:89-97

Khan S, Cao Q, Lin AJ, Zhu YG (2008a) Concentrations and bioaccessibility of polycyclic aromatic hydrocarbons in wastewater-irrigated soil using in vitro gastrointestinal test. Environ Sci Pollut Res Int 15:344-353

Khan S, Lin AJ, Zhang S, Hu Q, Zhu YG (2008b) Accumulation of polycyclic aromatic hydrocarbons and heavy metals in lettuce grown in the soils contaminated with long-term wastewater irrigation. J Hazard Mater 152:506-515

Martorell I, Perelló G, Martí-Cid R, Castell V, Llobet JM, Domingo JL (2010) Polycyclic aromatic hydrocarbons (PAH) in foods and estimated PAH intake by the population of Catalonia, Spain: temporal trend. Environ Int 36:424-432

McGrath TE, Wooten JB, ChanW G, Hajaligol MR (2007) Formation of polycyclic aromatic hydrocarbons from tobacco: the link between low temperature residual solid (char) and PAH formation. Food Chem Toxicol 45:1039-1050

Meng L, Qiao M, Arp HPH (2011) Phytoremediation efficiency of a PAH-contaminated industrial soil using ryegrass, white clover, and celery as mono- and mixed cultures. J Soils Sediments $11: 482-490$
Rattan RK, Datta SP, Chhonkar PK, Suribabu K, Singh AK (2005) Long-term impact of irrigation with sewage effluents on heavy metal content in soils, crops and groundwater - a case study. Agr Ecosyst Environ 109:310-322

Sanders M, Sivertsen S, Scott G (2002) Origin and distribution of polycyclic aromatic hydrocarbons in surficial sediments from the Savannah River. Arch Environ Contam Toxicol 43:438-448

Singh KP, Mohan D, Sinha S, Dalwani R (2004) Impact assessment of treated/untreated wastewater toxicants discharged by sewage treatment plants on health, agricultural, and environmental quality in the wastewater disposal area. Chemosphere 55:227255

Storer DA (1984) A simple high sample volume ashing procedure for determining soil organic matter. Commun Soil Sci Plant Anal 15:759-772

Tang L, Tang XY, Zhu YG, Zheng MH, Miao QL (2005) Contamination of polycyclic aromatic hydrocarbons (PAHs) in urban soils in Beijing, China. Environ Int 31:822-828

Tao S, Cui YH, Xu FL, Li BG, Cao J, Liu WX, Schmitt G, Wang XJ, Shen WR, Qing BP, Sun R (2004) Polycyclic aromatic hydrocarbons (PAHs) in agricultural soil and vegetables from Tianjin. Sci Total Environ 320:11-24

USEPA (2002) Polycyclic organic matter. Environmental Protection Agency, Washington, 2002. http://www.epa.gov/ttn/atw/hlthef/ polycycl.html. Accessed 10 June 2011

Wang YC, Qiao M, Liu Y-X, Arp HPH, Zhu Y-G (2011) Comparison of polycyclic aromatic hydrocarbon uptake pathways and risk assessment of vegetables from waste-water irrigated areas in northern China. J Environ Monit. doi:10.1039/c0em00098a

Wennrich L, Popp P, Zeibig M (2002) Polycyclic aromatic hydrocarbon burden in fruit and vegetable species cultivated in allotments in an industrial area. Int J Environ Anal Chem 82:677-690

Wild E, Dent J, Barber JL, Thomas GO, Jones KC (2004) A novel analytical approach for visualizing and tracking organic chemicals in plants. Environ Sci Technol 38:4195-4199

Ye Y, Zhang Z, Mao T (2006) Pollution sources identification of polycyclic aromatic hydrocarbons of soils in Tianjin area, China. Chemosphere 64:525-534

Zhang S, Zhang W, Shen Y, Wang K, Hu L, Wang X (2008) Dry deposition of atmospheric polycyclic aromatic hydrocarbons (PAHs) in the southeast suburb of Beijing, China. Atmos Res 89:138-148

Zhang Y, Zhu Y-G, Houot S, Qiao M, Nunan N, Garnier P (2011) Remediation of polycyclic aromatic hydrocarbon (PAH) contaminated soil through composting with fresh organic wastes. Environ Sci Pollut Res Int. doi:10.1007/s11356.011-0521-5 